\title{
AMO-DATA EN LA TAXONOMÍA Y EN EL MANEJO DE COLECCIONES
}

\author{
Eric HáGsater \& Luis M. SÁnchez-SaldaÑa \\ Herbario AMO, Apartado Postal 53-123, 11320, México, D.F. \\ ${ }^{1}$ Autor para correspondencia: eric@internet.com.mx
}

\begin{abstract}
Amo-Data es un sistema de bancos de datos, relacionados todos ellos entre sí, para el manejo de colecciones botánicas y taxonomía. Reúnen información de familias, géneros, especies, localidades, tipos de vegetación y nomenclatorial, entre otros; en sí, toda la información necesaria para los trabajos de tipo taxonómico de la familia Orchidaceae.

En sus inicios, Amo-Data fue diseñada en el Herbario AMO por Eric Hágsater y Kerry Walter en el manejador de bases de datos Revelation, entre los años 1984-1985. Contaba con cuatro bancos de información: el de géneros, el de países, el de colectas y el banco de ejemplares de herbario, los cuales pretendían cubrir la mayor cantidad de información posible de cada uno de los registros, basados en las etiquetas de colecta.
\end{abstract}

Posteriormente se inició el desarrollo de un banco de datos nomenclatorial para la familia Orchidaceae, con la idea de incluir todos los nombres disponibles para la familia, esto con la finalidad de obtener listados de los taxa con su sinonimia, además del manejo de la bibliografía básica.

Finalmente en colaboración de la Universidad Autónoma Metropolitana - Iztapalapa, se concretó una base de datos más completa, desarrollada en el programa comercial Advanced Revelation, el cual es un manejador de bases de datos de tipo relacional con campos de longitud variable, los cuales se ajustan automáticamente a la cantidad de información que contenga cada registro, además cuenta con campos de valor múltiple, los cuales nos permiten tener varios valores (nombres) en el mismo campo, y presenta campos simbólicos, los cuales permiten tener una mayor versatilidad en el manejo de la información de los diferentes registros.

Actualmente Amo-DATA cuenta con 27 bancos de información todos ellos interrelacionados entre sí. Dentro de ellos destaca el banco Colectas, que con- siste fundamentalmente de una libreta de colectas electrónica, en la cual se almacena toda la información recabada durante los viajes de recolección en el campo, por los diferentes colectores de la Institución y el banco de ESPECIMENES, basado en las etiquetas de los ejemplares de herbario, y que almacena toda la información contenida en éstas, permitiendo además capturar información de colecciones anexas al herbario como son: la diapoteca, flores preservadas en alcohol, ilustraciones y otras.

El banco denominado BibliografiA, contiene la información referente a los artículos en los que se describen especies nuevas, o bien, aquellos trabajos en los que se efectúan cambios nomenclatoriales o taxonómicos, permitiendo con ésto tener la referencia bibliográfica completa y detallada. Finalmente en el banco TAXA, se capturan todos los nombres válidamente publicados y aceptados, basándose principalmente en las descripciones originales, monografías, revisiones taxonómicas, etc. Este banco cuenta con la información de los sinónimos taxonómicos y nomenclatoriales para cada uno de los nombres aceptados.

Todos y cada uno de los bancos que forman AMODATA, dan como resultado una poderosa herramienta que ayuda a los trabajos florísticos y/o taxonómicos a obtener la información de manera fácil y ordenada. El procesamiento de todo el material mediante el uso del banco de Colectas es menos tedioso y con menos errores en el etiquetado del material, debido a que la información se teclea una sola vez y posteriormente se transfiere al banco de EsPECímENES. A partir de este banco se obtienen las etiquetas de herbario con sus respectivos duplicados, además de llevar un control preciso de lo que pasa con las plantas colectadas.

En lo que respecta a la revisión e identificación de todo el material botánico que se está estudiando, esta tarea se vuelve relativamente sencilla al utilizar con- 
juntamente los bancos ESPECÍMENES y TAXA, debido a que de una manera rápida se obtiene cualquier información disponible en las etiquetas de herbario, por ejemplo: todos los nombres que ha recibido un ejemplar de herbario y quién se lo asignó, el colector y su número de colecta, datos de ecología y distribución local y/o regional de una especie, si se trata de material tipo o no, sólo por mencionar algunos.

Mediante el uso de estos bancos es fácil localizar duplicados de una misma colecta depositados en diferentes instituciones, lo que nos permite identificar automáticamente todos los duplicados con la revisión de un solo ejemplar. Además, nos facilita la localización de material tipo no anotado como tal en las Instituciones, basándonos en la información disponible en la publicación original.

El poner en blanco y negro los resultados de nues- tro estudio, que es la última etapa de nuestro trabajo, se vuelve relativamente simple, ya que mediante una serie de listados, podemos obtener en cualquier orden resultados tales como: listados florísticos locales y/o regionales; listado del material revisado incluyendo la institución en que se encuentra depositado; lista de nombres aceptados con sus sinónimos nomenclatorirales y taxonómicos; cita bibliográfica de cada uno de los nombres utilizados en nuestro estudio, datos acerca de material tipo, etc.

Finalmente, con los 120 mil registros con los que cuenta AMO-DATA actualmente se han publicado 6 volúmenes de los Icones Orchidacearum, gran parte de la revista Orquídea (Méx.), entre otras. Además, la información con que cuenta AMO-DATA, está disponible a todos aquellos estudiosos que estén interesados en este tópico.

Eric Hágsater. Fundador de la Asociación Mexicana de Orquideología en 1969, Fundador y Director del Herbario AMO desde 1976. Es miembro y fundador de importantes Asociaciones y Fundaciones tanto de México como del extranjero. Especialista en el género Epidendrum L. (Orchidaceae), con más de 130 artículos publicados, principalmente en la taxonomía de orquídeas y en la conservación de las orquídeas en el Neotrópico. Editor de la revista Orquídea (Méx.) y de los Icones Orchidacearum, entre otras publicaciones. Ha diseñado y desarrollado Amo-DATA. Miembro desde 1994 del comité técnico de la REMIB (Red Mundial de Información sobre Biodiversidad), red interinstitucional que comparte información biológica. Está constituida por nodos, formados por los centros de investigación que albergan las colecciones científicas.

Luis Sánchez. Curador del Herbario AMO desde 1995 y responsable del manejo y funcionamiento de AMODATA. Colaborador de Eric Hágsater en el estudio del género Epidendrum L. (Orchidaceae) en el Neotrópico. Ha participado en diversos proyectos tanto de México como del extranjero. Coeditor de los Icones Orchidacearum desde 1997. 